forthcoming in Journal of Medical Ethics

\title{
Sexual Rights and Disability
}

\author{
Ezio Di Nucci
}

\begin{abstract}
I argue against Appel's (2010) recent proposal - in this JOURNAL - that there is a fundamental human right to sexual pleasure, and that therefore the sexual pleasure of severely disabled people should be publicly funded - by thereby partially legalizing prostitution. I propose an alternative that does not need to pose a new positive human right; does not need public funding; does not need the legalization of prostitution; and that would offer a better experience to the severely disabled: charitable non-profit organizations whose members would voluntarily and freely provide sexual pleasure to the severely disabled.
\end{abstract}

Appel (2010) [1] has recently argued in this JOURNAL in favour of sexual rights for the severely disabled: "For too long, our society has viewed these unfortunate individuals as non-sexual beings, adopting rules in matters such as consent and reimbursement that may serve the interests of able-bodied society, but do a profound disservice when applied to those with disabilities. If we are to overcome these obstacles, and to live in a more just civilization, we must begin to see sexual pleasure as a fundamental right that should be available to all" (2010: 154) [1].

Appel proposes that, in order for such right to be upheld, sexual services for the disabled be publicly funded: "we should seriously consider including sexual surrogacy for the disabled in the basket of services that we provide. Already, we have made the choice to pay for other purely social and cosmetic services to help unfortunate individuals lead more pleasurable and productive lives - such as breast reconstruction for mastectomy patients and plastic surgery for children born with cleft lips... Sexual pleasure ought not be viewed any differently. Most western healthcare systems acknowledge this, to some degree, paying for medications to treat erectile dysfunction in men and subsidising birth control pills for women... Any notion of healthcare broad 
enough to encompass cosmetic surgery ought to be generous enough to include funding for the sexual pleasure of the disabled... [which] should be covered by all public health systems and private insurance plans" (2010: 153) [1].

Here I present a better argument than Appel's to address his concerns about the sexual satisfaction of the severely disabled. I also believe that the sexual interests and needs of the severely disabled ought to be met. But I have three worries with Appel's strategy:

1) Should we meet the sexual interests of the disabled by introducing a right to sexual pleasure? A right that Appel describes as 'fundamental', perhaps hinting to the stronger view that it should be an inalienable human right?

2) Should we meet the sexual interests of the disabled by appeal to the public purse? Sexual satisfaction for the severely disabled, according to Appel, "should be covered by all public health systems and private insurance plans" (2010: 153). [1]

3) Should we meet the sexual interests of the disabled by a restricted legalization of prostitution, as Appel argues for? "If sexual pleasure is a fundamental right, as this author believes, then jurisdictions that prohibit prostitution should carve out narrow exceptions for individuals whose physical or mental disabilities make sexual relationships with non-compensated adults either impossible or highly unlikely." (2010: 153). [1]

\section{Is there a right to sexual pleasure?}

I am going to discuss my objections and then develop a superior proposal with the same goal: meeting the sexual interests of the severely disabled. First of all, let me emphasize that Appel and I agree on the central issues: severely disabled individuals do not necessarily lose their sexual interests solely in virtue of their disability. So there are severely disabled individuals who have sexual interests but, because of their disability, find it much harder than others - often impossible without assistance - to satisfy their sexual interests.

So I agree with Appel that there is a problem, and that this is an important moral problem: there are individuals with legitimate interests which find it very difficult if not impossible to satisfy those legitimate interests without external assistance. That is precisely the framework within which society's intervention is called for. It is exactly within this framework that people routinely call for ambulances or the police: their own or someone else's legitimate interests in not being mugged, stalked, raped, or killed - in the case of the police; their own or someone's else legitimate interests in not bleeding to death, or lose a limb, or die of an heart attack - in the case of ambulances. A citizen has a legitimate interest that she wants upheld, so she calls in the state for help. So far, so good. So should there be a public service that severely disabled people (or more likely 
someone on their behalf) can call upon for the satisfaction of their legitimate sexual interests?

The 'legitimate interests satisfaction' framework that I have developed above does not just apply to calls to the police or the ambulance service. It also applies to pizza deliveries. A citizen has a legitimate interest that she wants upheld - she wants a pizza without having to leave the house - so she calls pizza delivery. Now it might be argued that if pizza deliveries had not proved to be a legal and commercially successful enterprise (maybe because of ancient prejudices like those against prostitution), then the state should come in and guarantee pizza delivery by public funding. But, more likely, the pizza delivery example shows that it is not enough that citizens - any citizen, more or less vulnerable - have legitimate interests for those interests to need, thereby, to be met with legislation and public funds.

This is indeed why Appel must talk not just of legitimate interests, but of rights. But the problem, with 'rights' talk in this context, is, firstly, in having to establish whether sexual services are more like the ambulance service and the police rather than pizza delivery. Secondly, we must either grant everybody the right to sexual satisfaction, or we must argue that severely disabled people have, in virtue of their increased difficulty to satisfy their sexual interests, a right to sexual services that non-severely disabled people do not have. Let me emphasize that these two options are genuinely alternative: namely, the latter is incompatible with the former. If sexual satisfaction (where physically possible, that is) is a human right, then severely disabled people do not have more of a right to it than everybody else.

I have made this last point to bring out a problem with Appel's argument: if sexual satisfaction is a human right - as he suggests; and if such human right is to be met through the public purse - as Appel also suggests; then we would end up with a situation in which severely disabled people have their sexual satisfaction paid for them by the state, while everybody else will have to pay for it, or go through the trouble of finding willing non-compensated sexual partners. What this problem emphasizes is a simple point: if sexual satisfaction were really a fundamental human right, then the state would have to provide for everybody.

So what of this alternative idea that severely disabled people have a unique right to sexual satisfaction that everybody else does not share? This must be distinguished from the superficially similar idea that we all have an equal right but that severely disabled people justly require that more resources be spent for the upholding of their right. So that I might not be entitled to an ambulance for a routine hospital visit if I can easily and inexpensively arrange the transport myself; but a severely disabled person would rightly be picked up by an ambulance if necessary. This latter version is easily justifiable by appeal to the equal right of which above. But here we are now saying that severely disabled people have a right to sexual satisfaction that everybody else does not have. 
How might we justify such a unique (and therefore unequal) right? This, again, couldn't be justified in the way in which we justify dedicated toilets or ramps: those are ways to ensure equal access. But here we are talking of a right to sexual satisfaction that only the severely disabled would have.

One such justificatory story could go as follows: the severely disabled have been unfortunate enough in life to deserve something more than everybody else, a unique right to sexual pleasure. We are making amends for the cruelty of both nature and past generations. Two issues here: why, in particular, the right to sexual satisfaction?

Secondly, it is not at all clear that we should or could make amends by granting a unique right - especially one that is unrelated to the distinctive condition of those to which we would grant it. Again, there might be considerations of equality of access that justify increased resources for the disabled. But that wouldn't be because being severely disabled has any unique connection to sexual satisfaction. It could only be because despite being severely disabled, individuals have sexual interests and we should facilitate the satisfaction of their sexual interests because their independent access to it is impaired. But this framework would in turn depend on an equal human right for sexual satisfaction - a right which Appel has assumed but not argued for; and a right which is, as we discussed above, problematic.

It must also be emphasized that the right to sexual pleasure that Appel advocates is a so called positive right as opposed to a negative right. ${ }^{1}$ Appel is not only advocating an individual's right not to be constrained or interfered with in her sexual attitudes and behaviours. Appel is also advocating an individual's right against the state to be provided with sexual pleasure. I say this to emphasize that there is a kind of sexual rights the universality of which almost nobody (and certainly not I) would deny, but these sexual rights are not those advocated by Appel. The negative sexual rights to choose and practice one's sexual attitudes, orientation, and partners are well-established. But those negative rights do not bear on an individual's positive sexual rights to sexual pleasure advocated for by Appel, and that I have argued against here. So not only is it perfectly consistent to defend negative sexual rights to sexual self-determination and deny positive sexual rights, as I do here. But also negative sexual rights to sexual selfdetermination are no argument against my discussion here, and no argument in favour of Appel.

Appel's advocacy of positive sexual rights has a fundamental flaw: universal positive sexual rights are incompatible with universal negative sexual rights. If $A$ has a positive sexual right, then that means that there is at least one person which would lack negative sexual rights. Namely the person which would be supposed to fulfill A's positive sexual rights. If everybody has negative sexual rights, then everybody has the right to refuse to

1 See Narveson 2001 [3] for a standard account of the distinction. Appel himself explicitly appeals to the difference between a negative rights conception of sexual liberty and a positive rights conception throughout his paper (pp. 152-153). 
fulfill A's sexual needs: but then A has no positive right to sexual pleasure.

This standard distinction between positive rights and negative rights serves me well to explain why I think that the sexual interests of disabled people ought to be met even though I don't think that disabled people have a right to sexual pleasure. ${ }^{2}$ Firstly, now it should be clear that when I deny that disabled people have a right to sexual pleasure, I deny that they have a positive right to sexual pleasure; namely one that ought to be met by the state through public funds. That does not mean that they don't, normally, have a negative right to sexual pleasure. Within certain caveats meant to prevent abuse (which I discuss at the end of the paper), it is wrong to prevent disabled people from satisfying their sexual interests: that is the sense in which they have a negative right to sexual pleasure. And that's the sense in which I think that it would be worthy to pursue their sexual satisfaction even though I don't think that they have a positive right to said sexual satisfaction. This also illustrates the difference between a positive right to sexual pleasure and a legitimate interest in sexual pleasure (one's legitimate interest, when it is not incompatible with someone else's legitimate interest, is just a negative right). My alternative proposal below is meant precisely to pursue the sexual satisfaction of disabled people without needing to appeal to their positive right to sexual pleasure; without having to appeal to the public purse; and without having to legalize prostitution.

\section{An alternative proposal}

To sum up, I have argued against Appel's claim that there is a fundamental human right to sexual pleasure; and I have argued against an alternative possible premise that the severely disabled have a unique right to sexual pleasure. Appel's other two claims that I take issue with - the proposal to publicly fund the sexual satisfaction of the severely mentally disabled, and the consequent need to (partially) legalize prostitution - depend on his claim about the positive human right to sexual satisfaction. What justifies the appeal to public funds is this new right; and what requires the (partial) legalization of prostitution is also the upholding of this new right.

I will discuss these other two claims in the context of my alternative proposal, because the appeal to public funds and the need to legalize prostitution make it obvious why my proposal is superior: my proposal makes no appeal to public funds, and it does not require even a partial legalization of prostitution. I propose that the sexual interests and needs of the severely disabled be met by charitable non-profit organizations, whose members would voluntarily and freely provide sexual pleasure to the severely disabled. ${ }^{3}$

This has multiple obvious advantages over Appel's proposal. Before analyzing those, let me say that my proposal would achieve exactly the same goal as Appel's: the satisfaction of the sexual interests and needs of the severely disabled. Indeed, we will

2 Thanks to an anonymous referee for pressing me on this point.

3 Appel (2010: 153) [1] himself mentions non-profit projects. See also the TLC Trust, a UK charity which connects disabled individuals with sex workers (http://www.tlc-trust.org.uk/). 
see later on that my proposal might do even better than that. First, though, its advantages. First of all, the obvious ones in the context of my argument against Appel: first, my proposal needs no theoretically and metaphysically problematic appeal to rights. Second, my proposal requires no public money. Third, my proposal does not require, for its implementation, the legalization of prostitution, because everything would happen in a fully voluntary and non-commercial context. So my proposal has none of the problems of Appel's.

But, the reader will object, I have yet to show that the last two - appeal to public funds and legalization of prostitution - are indeed problems. Here I mean problems in a bare political sense: the need for both more money and a change in the law are, in themselves, obstacles to the implementation of any proposal. So in this sense these two constitute problems independently of what one's other political beliefs are: independently, for example, of whether one thinks that prostitution is wrong. Or of whether one thinks that prostitution should not be legalized - the former does not imply the latter, by the way. Independently, also, of one's more general political inclinations to do with the role of the state and taxation.

The sexual interests and needs of the disabled have sometimes been appealed to, in the literature, to justify prostitution. Fabre (2006: 163) [2] cites a touching letter to The Observer newspaper (6 April 2003) from someone praising the work of prostitutes because of what they do, for example, for the disabled:

As a single man who visits prostitutes, I object to being branded... a sad creature who must pay for his thrills. Most clients of these patient, sympathetic and compassionate ladies are, like me, disabled, elderly, disfigured, ugly or socially or sexually inadequate. The prostitute provides the only opportunity for a brief, life-enhancing taste of physical affection. God bless her! (Name and address withheld) [2]

But Appel's theme is not the justification of prostitution: it is just that his argument needs the legalization of prostitution. By endorsing my alternative we achieve the same result wished for by Appel without needing to change the law with regards to prostitution, and we also do justice to arguments like the one reported by Fabre: indeed, providing sexual satisfaction for the disabled is a worthy endeavour. ${ }^{4}$

There are other advantages to my argument: by making this service wholly voluntary and non-commercial, we likely guarantee a better experience for those involved; the severely disabled would probably enjoy it more in virtue of the fact that the service would be independent, voluntary, charitable, non-profit, and non-commercial. Indeed,

4 To be clear: my view is that prostitution ought to be legalized (see Nussbaum 1998 [4] for an excellent discussion). But the issue is both theoretically and politically complicated, and therefore it is an advantage of my argument that it does not depend on any position on this topic. 
Appel's discussion suggests that he would probably agree on this point: "it is not merely sexual stimulation that is an essential human right, but also the sexual pleasure that stems from relations between consenting individuals" (2010: 152) [1].

This suggests that a voluntary non-profit relationship would be more beneficial to the severely disabled (and their families): because those volunteers involved would be doing it solely and essentially for the benefit of the severely disabled. They would have joined the organization upon recognizing the obvious moral worth of the cause. They would be committed to it in a way that professionals couldn't. And their motivation would be uncontaminated in a way in which a professional's motivation could never be. The relationship between volunteers and the severely disabled would be intimate, private, and personal in a way in which a professional public-run service could not be. All this, by the way, would not mean that the service would in any way lose out in terms of standards: there are plenty of professionally-trained experts working in the charitable non-profit sector.

Another advantage of my proposal is in terms of access: if sexual pleasure for the severely disabled was to be made a responsibility of publicly funded health services, then its operations - in particular who would get access to the services - would depend in turn on the controversial definitional issues surrounding health and illness. Would it be enough to gain access, for example, to have a history of complete failure to find sexual partners? Probably not. But why? Old 'dualistic' issues would come to haunt such a service, and probably law suits too! With fully voluntary non-profit organizations whose own members directly engage with the severely disabled these problems would not arise: the volunteers themselves could, freely, decide what to do within the organization's regulations. And there is no great risk of the service I envisage being normally overrun, just like soup-kitchens are not normally overrun.

A supporter of Appel's proposal might object that my alternative is weak with respect to the issue of the vulnerability of severely disabled individuals. Obviously their psychological and physical safety is paramount. But I don't think that charitable nonprofit organizations would put that at risk. If anything, as I already said, I think that volunteers would care for these severely disabled individuals more and better than professional sex workers. Also, this vulnerability objection rings odd coming from someone who agrees with Appel: after all, part of the point of both Appel's proposal and mine is exactly to decontaminate the issue of sex for the severely disabled. And to appeal back to their vulnerability now would weaken the whole trust of our common goal: the satisfaction of the sexual interests and needs of severely disabled individuals.

On the one hand, then, the issue of vulnerability is no reason to choose Appel's proposal over mine. But on the other hand this is clearly a central issue when talking about sex and disability. ${ }^{5}$ Here the distinction between physical disability and mental disability is

5 Thanks to an anonymous referee for raising this point. 
particularly important because only certain kinds of disabilities raise the issue of consent. And it is consent (and the related risk of abuse) that is the worry when discussing ways to pursue the sexual satisfaction of the mentally disabled.

Let us first of all emphasize that there are scores of physically disabled people for which the initiative I have described would be greatly beneficial, and for whom the issue of consent does not arise: many disabilities do not in any way constrain an individual's capacity to offer their consent. The issue of consent is therefore relevant in only certain cases, so that it is no reason to disregard the proposal altogether. It is rather reason to work out carefully who should be the recipient of such a service.

It is beyond the scope of this paper to go into the details of which disabilities would impair consent, but certainly there will be cases in which a mentally disabled individual should not be offered this service because she is not able to give her consent and she is at risk of abuse. Being a philosopher, I will have to defer to other and higher authorities on the issue of precisely who should avail of my proposal and who shouldn't. ${ }^{6}$ My point here is that issues of vulnerability and consent are, firstly, no grounds to choose Appel's proposal over mine; and secondly, and more importantly, no grounds to disregard the proposal altogether but rather to pay extreme care to which individuals should be involved. I say, with Appel: "Just because these individuals are vulnerable does not mean that all contact should be assumed to be unwanted" (p. 153).

Let's take stock: on my proposal, the sexual satisfaction of the severely disabled would be guaranteed by charitable non-profit organizations. My proposal has several advantages over Appel's: it stipulates no fundamental human right to sexual pleasure. It requires no public money. It does not require the legalization of prostitution. And it offers a more fulfilling service for the severely disabled.

Universität Duisburg-Essen

45117 Essen, Germany

ezio.dinucci@uni-due.de

6 I imagine that doctors, psychologists, and carers should be involved in deciding whether a particular individual should be allowed to participate. And I imagine that sometimes the decision will be extremely difficult and that therefore the safer option will be to not allow it. But those aren't, again, reasons to deny sex to those disabled people which could be safely involved. Nor are they reasons to think that this service could not be successfully carried out by the voluntary non-profit sector. 


\section{References}

(1) Appel, J.M. (2010), 'Sex rights for the disabled?', Journal of Medical Ethics 36: 152-154.

(2) Fabre, C. (2006), Whose Body Is It Anyway? Oxford UP.

(3) Narveson, J. (2001), The Libertarian Idea. Broadview.

(4) Nussbaum, M. (1998), 'Whether from Reason or Prejudice: Taking Money for Bodily Services', Journal of Legal Studies 27 (2): 693-724. 